\title{
Transperitoneal laparoskopik radikal nefrektomi uygulanan büyük ve küçük renal kitlelerin sonuçlarının karşılaştırılması
}

\author{
Comparison of the results of large and small renal masses under transperitoneal \\ laparoscopic radical nephrectomy
}

\author{
Sinan Çelen, Yusuf Özlülerden, Aykut Başer, Salih Bütün
}

Gönderilme tarihi: 19.06 .2020

Kabul tarihi: 02.12.2020

Özet

Amaç: Laparoskopik radikal nefrektomi (LRN) uygulanan $8 \mathrm{~cm}$ veya daha büyük renal kanserler (RK) ile $8 \mathrm{~cm}$ altı RK'lerin perioperatif ve postoperatif sonuçlarını karşılaştırmayı amaçladık.

Gereç ve yöntem: Hastanemizde 2018-2020 yılları arasında, tek bir cerrah tarafından, LRN uygulanan 35 hasta gözden geçirildi. Etik kurulu onayı sonrasında, patoloji raporu temel alınarak, tümör büyüklüklerine göre, kitleler küçük boyutlu (tümör boyutu $<8 \mathrm{~cm}$ ) ve büyük boyutlu (tümör boyutu $\geq 8 \mathrm{~cm}$ ) olarak 2 gruba ayrıldı. Demografik özellikler, ameliyat süreleri, yatış süreleri, komplikasyonlar ve açık cerrahi gereksinimleri her grup için ayrı ayrı değerlendirildi.

Bulgular: Küçük boyutlu RK grubu (Grup 1) ve büyük boyutlu RK grubu (Grup 2) sırasıyla 19 ve 16 hastadan oluşmaktaydı. İki grup yaş, cinsiyet, vücut kitle indeksi açısından karşılaştırıldı ve benzer bulundu (sırasıyla 0,960; 0,612 ve 0,203). Grup 1 hastalarında anlamlı olarak daha az kan kaybı (sırasıyla, 80,7 $\pm 56,57 ; 126,87 \pm 66,3$; $p=0,002$ ) ve daha kısa ameliyat süresi (sırasıyla $87,36 \pm 15,21 ; 103,12 \pm 11,38$ dakika, $p=0,001$ ) izlendi.

Sonuç: Verilerimiz LRN ile büyük boyutlu renal tümörlere de güvenle cerrahi uygulanabileceğini göstermiştir. Laparoskopik deneyime sahip ürologlar LRN endikasyonlarını genişletmeyi düşünmelidir.

Anahtar kelimeler: Laparoskopi, radikal nefrektomi, böbrek kanseri.

Çelen S, Özlülerden Y, Başer A, Bütün S. Transperitoneal laparoskopik radikal nefrektomi uygulanan büyük ve küçük renal kitlelerin sonuçlarının karşılaştırılması. Pam Tıp Derg 2021;14:209-213.

\begin{abstract}
Purpose: We aimed to compare the perioperative and postoperative results of laparoscopic radical nephrectomy (LRN) in renal cancers (RC) of $8 \mathrm{~cm}$ or larger and those of less than $8 \mathrm{~cm}$.

Materials and methods: 35 patients who underwent LRN by a single surgeon between 2018-2020 in our hospital were reviewed. After the approval of the ethics committee, based on the pathology report, the masses were divided into 2 groups according to tumor size as small size (tumor size $<8 \mathrm{~cm}$ ) and large size (tumor size $\geq 8$ $\mathrm{cm}$ ). Demographic characteristics, operation times, length of stay, complications and open surgery requirements were evaluated for each group.

Results: The small-sized RC group (Group 1) and the large-sized RC group (Group 2) consisted of 19 and 16 patients, respectively. The two groups were compared in terms of age, gender, body mass index and were found to be similar $(0.960,0.612$ and 0.203 , respectively). Group 1 patients had significantly less blood loss $(80.7 \pm 56.57 ; 126.87 \pm 66.3 ; p=0.002$, respectively) and shorter operative time $(87.36 \pm 15.21 ; 103.12$, respectively). \pm 11.38 minutes, $p=0.001$ ).

Conclusion: Our study showed that LRN can be safely applied to large-sized renal tumors. Urologists with laparoscopic experience should consider expanding the LRN indications.
\end{abstract}

Key words: Laparoscopy, radical nephrectomy, renal cancer.

Celen S, Ozlulerden Y, Baser A, Butun S. TComparison of the results of large and small renal masses under transperitoneal laparoscopic radical nephrectomy. Pam Med J 2021;14:209-213.

Sinan Çelen, Dr. Öğr. Üye. Pamukkale Üniversitesi Tıp Fakültesi, Üroloji Anabilim Dalı, Denizli, Türkiye, e-posta: sinancelen@hotmail.com (https://orcid.org/0000-0003-4309-2323) (Sorumlu Yazar)

Yusuf Özlülerden, Dr. Öğr. Üye. Pamukkale Üniversitesi Tıp Fakültesi, Üroloji Anabilim Dalı, Denizli, Türkiye, e-posta: yusufozlu35@hotmail. com (orcid.org/0000-0002-6467-0930)

Aykut Başer, Dr. Öğr. Üye. Hitit Üniversitesi Tıp Fakültesi, Üroloji Anabilim Dalı, Çorum, Türkiye, e-posta: aykutbaser@mynet.com (orcid. org/0000-0003-0457-512X)

Salih Bütün, Arş. Gör. Dr. Pamukkale Üniversitesi Tıp Fakültesi, Üroloji Anabilim Dalı, Denizli, Türkiye, e-posta: salihbutun92@gmail.com (orcid. org/0000-0002-5969-0371) 


\section{Giriş}

1991 yılında ilk uygulanması sonrasında, laparoskopik radikal nefrektomi (LN) renal kitlelerinin tedavisinde giderek yaygınlaşmıştır [1]. Çok sayıda ve geniş hasta serili çalışmalarda LRN açık radikal nefrektomiye (ARN) benzer onkolojik sonuçlar bildirilmiştir. Bununla birlikte hastanede kalış süresinin kısa olması, analjezi gereksiniminin az olması, daha iyi kozmetik sonuçlar gibi LRN lehine olabilecek sonuçlar bildirilmiştir [2-8]. Birçok merkezde LRN, nefron koruyucu cerrahiye aday olmayan hastalarda renal kitlelerin cerrahisinde standart yaklaşım olmuştur [9-11]. Bizde büyük boyutlu böbrek tümörlerinde LRN'nin güvenliğini ve etkinliğini değerlendirmek için, boyutu $8 \mathrm{~cm}$ ve üstü olan kitleler ile $8 \mathrm{~cm}$ altında olan kitleleri karşılaştırmalı olarak değerlendirdik.

\section{Gereç ve yöntem}

Pamukkale Üniversitesi Girişimsel Olmayan Klinik Araştırmalar Etik Kurulu'nun onayı alındıktan sonra, 2018 ve 2020 yılları arasında kliniğimizde renal kitle nedeni ile LRN uygulanan 52 hasta geriye dönük olarak değerlendirildi. Sonuç patolojisi benign olarak görülen hastalar çalışma dışı bırakıldı. Tüm ameliyatlar tek cerrah tarafından uygulandı. Hastaların yaşı, cinsiyet, vücut kitle indeksi ve Amerikan Anestezistler Derneği (ASA) sınıflandırması dahil olmak üzere demografik verileri kaydedildi. Ameliyat süresi, ortalama kan kaybı (OKK), transfüzyon gereksinimleri, patolojik tümör tipi, tümör boyutu, ameliyat süresi, hastanede kalış süresi, GFR azalışı, hemoglobinde azalma oranı, komplikasyon oranları değerlendirildi. İstatistiksel analizler SPSS 23,0 versiyonu (Statistical Package for the Social Sciences Inc. Chicago, IL, ABD) kullanılarak gruplar arası analiz uygulandı. Verilerin normal dağılımı görsel olarak ve kolmogorov smirnov testi kullanılarak değerlendirdi. İki bağımsız grup arasında ki ortalamanın karşılaştırı masında veriler normal dağılım gösteriyor ise Stutend t test, normal dağılım göstermiyorsa Mann Whitney-U testleri kullanıldı. Kategorize verilerin karşılaştırılmasında ki-kare / fisher exact test kullanıldı. $P$ değeri 0,05 'in altındaki değer anlamlı kabul edildi.

\section{Bulgular}

LRN uygulanan 35 hasta çalışmaya dahil edildi. Patoloji raporlarına göre böbrek tümörü boyutları hesaplanarak hastalar iki gruba ayrıldı. Toplam 35 hastadan 19 tanesi böbrek tümörü $8 \mathrm{~cm}$ altında (Grup 1), 16 tanesi $8 \mathrm{~cm}$ üstünde olan (Grup 2) hastalardı. Hastaların tamamına transperitoneal teknik uygulandı. Hastaların klinik özellikleri değerlendirildiğinde, grup 1'de iki hastada, grup 2'de üç hastada tanı anında metastatik hastalık varlığı mevcut idi ve sitoredüktif cerrahi uygulandı. Cerrahi sınır tüm hastalarda negatif idi. Hastaların özellikleri Tablo 1'de özetlenmiştir. 3 hastada ileri derecede çevre dokulara yapışıklık olması nedeni ile cerrahi sırasında elektif olarak açığa geçilmiştir. Kanama nedeni ile açığa geçiş uygulanmamıştır. Takipte nüks izlenmemiş olup, sitoredüksiyon nedeni ile yapılan cerrahiler haricinde uzak metastaz gelişen hasta izlenmemiştir. Komplikasyonlar değerlendirildiğinde, clavien derece 3 ve 4 komplikasyon izlenmemiş olup, 6 hastaya peroperatif dönemde veya sonrasında eritrosit süspansiyonu transfüzyonu uygulanmıştır. Bunun dışında cerrahi müdahale ya da medikal tedavi gerektirecek komplikasyon izlenmemiştir. Hastaların operasyon süreleri (Grup1: $87,36 \pm 15,21$ dakika; Grup 2: 103,12 $\pm 11,38$ dakika; $p=0,001$ ) grup 1'de anlamlı olarak daha yüksek olup, kanama miktarları da (Grup 1: $80,7 \pm 56,57 \mathrm{ml}$; Grup 2: $126,87 \pm 66,3 \mathrm{ml}$; $p=0,002)$ yine bu grupta anlamlı olarak daha fazla izlenmiştir (Tablo 2). 
Tablo 1. Tümör boyutları $\leq 8 \mathrm{~cm}$ olan ve $>8 \mathrm{~cm}$ olan hastaların klinik özelliklerinin karşılaştırılması

\begin{tabular}{|c|c|c|c|c|}
\hline & & \multicolumn{2}{|c|}{ Tümör boyutu } & \multirow{2}{*}{$p$ değeri } \\
\hline & & $<8 \mathrm{~cm}$ & $8 \mathrm{~cm} \geq$ & \\
\hline \multicolumn{2}{|c|}{ Hasta sayısı (n) } & 19 & 16 & \\
\hline \multicolumn{2}{|c|}{ Yaş (yıl) (Ortalama \pm SD) } & $60 \pm 13,11$ & $59,75 \pm 11,5$ & 0,960 \\
\hline \multicolumn{2}{|c|}{ Cinsiyet (Erkek) } & $9(47,4)$ & $11(68,8)$ & 0,203 \\
\hline \multicolumn{2}{|l|}{ VKI (kg/m2) } & $28,6 \pm 4,32$ & $29,73 \pm 6,54$ & 0,612 \\
\hline \multicolumn{2}{|c|}{ Diabet sayı n (\%) } & $5(26,3)$ & $3(18,8)$ & 0,700 \\
\hline \multicolumn{2}{|c|}{ Hipertansiyon n (\%) } & $8(42,1)$ & $6(37,5)$ & 0,780 \\
\hline \multirow{4}{*}{ ASA skoru } & 1 & 3 & 1 & \multirow{4}{*}{0,328} \\
\hline & 2 & 10 & 13 & \\
\hline & 3 & 5 & 2 & \\
\hline & 4 & 1 & 0 & \\
\hline \multirow{4}{*}{ Patolojik evre } & T1a & 2 & 0 & \multirow{4}{*}{0,084} \\
\hline & T1b & 1 & 0 & \\
\hline & $\mathrm{T} 2$ & 7 & 2 & \\
\hline & T3 & 9 & 14 & \\
\hline
\end{tabular}

Tablo 2. Tek değişkenli cox regresyon modeli ile rekürrensi etkileyen risk faktörlerinin analizi

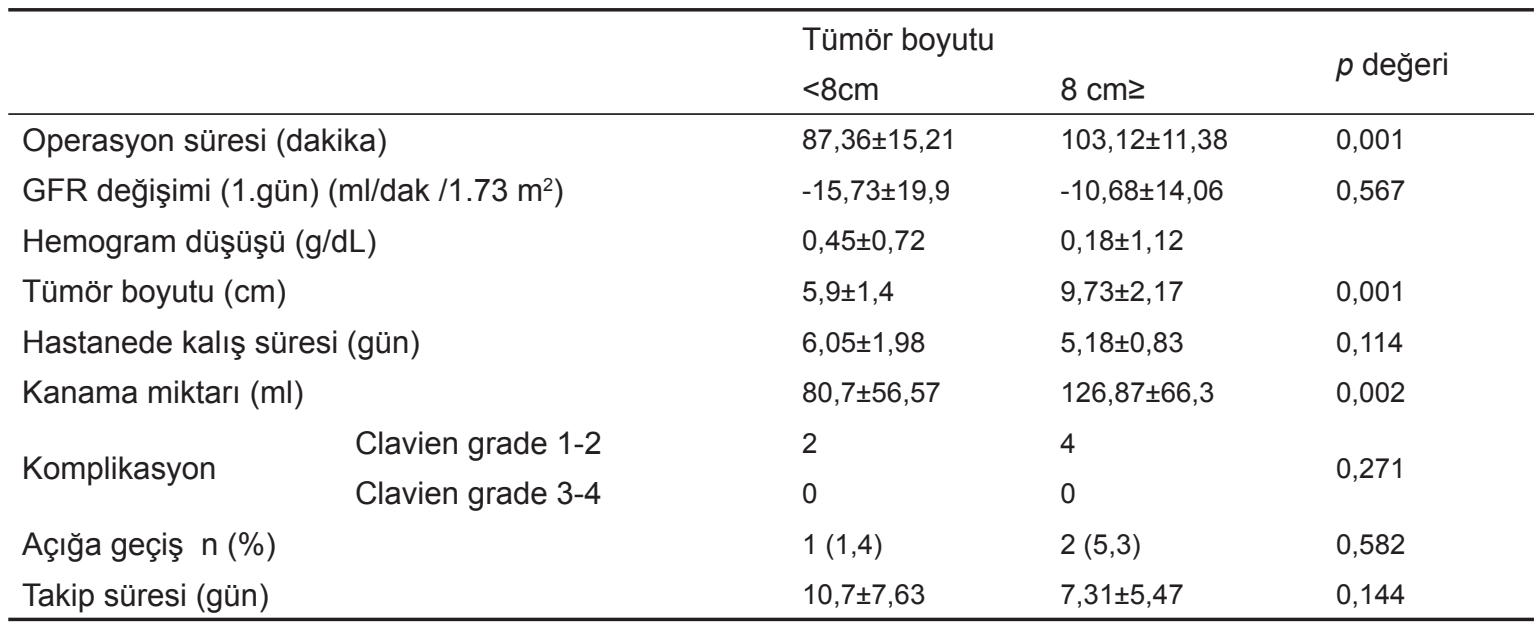

$\mathrm{cm}$ : santimetre, ml: milimetre

\section{Tartışma}

LRN ile ARN'nin karşılaştırıldığı çalışmalarda, onkolojik sonuçların benzer olduğu, hasta iyileşmesi ve günlük hayata dönüş açısından ise LRN'nin üstün olduğu bildirilmiştir [2-8]. ARN'nin komplikasyon oranlarının \%20 civarında olduğu, operasyon sırasında mortalitenin \%2 oranında olduğu bildirilmiştir [9]. Onkolojik sonuçların ARN ile benzer olması ve bunun yanında azalmış morbidite avantajları nedeni ile parsiyel nefrektomiye uygun olmayan birçok hasta grubu için LRN birçok merkezde klinik evre 1 tümörler için giderek yaygınlaşan oranda uygulanmaya başlamıştır. Ürologlar arasında LRN yaygınlaştıkça ve buna parelel olarak deneyim kazanıldıkça, LRN için endikasyonlar genişlemeye başlamış ve daha büyük ve karmaşık kitleler için ve sitoredüktif cerrahi için uygulanmaya başlanmıştır [10-12]. Büyük renal tümörlerde daha az çalışma alanı olması, renal hilusa ulaşımda zorluk, renal ven tümör trombüsü ile karşılaşma olasılığında artış, damar sayısında artış, kitleye bağlı damarların yer değiştirmesi ve anotominin bozulması gibi nedenlerden dolayı LRN daha zorlu hale gelebilmektedir. Bizim verilerimizde yine bu sebeplere bağıı olarak $8 \mathrm{~cm}$ üstü tümörlerde ameliyat süresinin uzadığı görülmüştür. Bununla birlikte eritrosit süspansiyonu transfüzyon sayısı $8 \mathrm{~cm}$ üstü tümörlerde sayısal olarak 
daha fazla idi. Ancak hemogram düşüşünde anlamlı farklılık izlenmedi. Bunun nedeni büyük tümörü olan grupta başlangıç hemoglobin değerlerinin daha düşük olması olabilir. Uzun ameliyat süresi ile ilişkilendirilebilecek venöz tromboz, pulmoner emboli, kardiak olaylar gibi durumların sayısında artış izlenmedi. GFR değerlerine bakıldığında ameliyat sonrası birinci gün değerlerinde anlamlı farklııık izlenmemiş olup uzun dönem değerler elde edilememiştir.

Steinberg ve ark.'nın [13] T2 tümörü olan hastalara uyguladıkları LRN serisinde kan transfüzyon oranlarını daha yüksek bulmuşlar ancak verilerini ARN ile karşılaştırdıklarında daha az morbidite oranları elde etmişlerdir. Verilerimizde kan transfüzyon sayıları istatiksel olarak anlamlı değilse de sayı olarak $8 \mathrm{~cm}$ üstü tümörlerde daha fazladır. Gong ve ark. tarafından yayınlanan çalışmasında, tek cerrah tarafından yapılan, klinik evre T2 olan hastalardaki LRN bulguları, T1 evreye göre kıyaslandığında daha uzun ameliyat süresi ve daha fazla kan transfüzyon oranları bildirmiş olup, bunula birlikte postoperatif komplikasyon oranı ve hastanede kalış sürelerinin benzer olduğunu bildirmişlerdir [14]. El yardımlı teknik kullanarak uygulanan LRN serilerinde de benzer komplikasyon ve hastanede kalış süresi bildirmişlerdir [15, 16]. LRN'nin sitoredüktif amaçlı kullanımını değerlendiren, MD Anderson Kanser Merkezi, Cleveland Clinic ve Ulusal Kanser Enstitüsü'nden bildirilen serilerde zaten metastaz yapmış büyük böbrek kitleleri için LRN'nin güvenliğini ve etkinliğini göstermiştir [10-12]. Bu sonuçlar değerlendirildiğinde LRN'nin dolaylı faydasının hastanın daha hızlı iyileşmesi ile sitoredüktif cerrahi sonrası sistemik tedavinin daha erken başlayabilmesidir.

Nefron koruyucu cerrahinin özellikle klinik evre 1 tümörlerde kullanımının yaygınlaşması ile, LRN'nin büyük boyutlu tümörlerde kullanımı da buna parelel olarak artacaktır. Bu nedenle yüksek evreli tümörlerde LRN kullanımı değerlendirilmesi önemlidir. Yapılan bir kohort çalışmada, $7 \mathrm{~cm}$ üstü tümörlerde 23 açık retroperitoneoskopik nefrektomi ile 25 açık nefrektomiyi karşılaştırmış ve laparoskopik vakaların daha az kan kaybı, daha az analjezi gereksinimi ve daha kısa hastanede kalış süresine sahip olduğunu bildirmişlerdir [17].

$\mathrm{Bu}$ çalışmanın retrospektif olması, hasta sayısının az olması ve açık seriler ile karşılaştırılması olmaması, bu bildirinin eksikleridir. Bununla birlikte serimizde bildirdiğimiz komplikasyon ve morbidite oranlarımızın daha önceki çalışmalarda bildirilen serilere oranla daha azdır.

Sonuç olarak, LRN endikasyonları, daha büyük ve daha karmaşık renal kitleleri içerecek şekilde artmaya devam etmektedir. Verilerimiz $8 \mathrm{~cm}$ veya daha büyük renal tümörü olan hastalarda LRN uygulanması sırasında perioperatif morbiditede sadece minimal bir artışa neden olduğu ve takip süresi boyunca onkolojik etkinliğe sahip olduğunu göstermektedir. LRN'nin ağrı, kozmetik ve yara iyileşmesi açııından iyi bilinen faydaları vardır ve sitoredüksiyon için kullanıldığında hastaların daha erken adjuvan tedaviye başlamasına izin verebilir. Laparoskopik deneyime sahip ürologlar, LRN endikasyonlarını daha büyük böbrek kitlelerini içerecek şekilde genişletmeyi düşünmelidir.

Çıkar ilişkisi: Yazarlar çıkar ilişkisi olmadığını beyan eder.

\section{Kaynaklar}

1. Clayman RV, Kavoussi LR, Soper NJ, et al. Laparoscopic nephrectomy: initial case report. J Urol 1991;146:278-282. https://doi.org/10.1016/s0022$5347(17) 37770-4$

2. Chan DY, Cadeddu JA, Jarrett TW, Marshall FF, Kavoussi LR. Laparoscopic radical nephrectomy: cancer control for renal cell carcinoma. J Urol 2001;166:2095-2099. https://doi.org/10.1016/s00225347(05)65513-9

3. Ono $\mathrm{Y}$, Kinukawa T, Hattori R, Gotoh M, Kamihira O, Ohshima S. The long-term outcome of laparoscopic radical nephrectomy for small renal cell carcinoma. J Urol 2001;165:1867-1870. https://doi. org/10.1097/00005392-200106000-00006

4. Gill IS, Meraney AM, Schweizer DK, et al. Laparoscopic radical nephrectomy in 100 patients: a single center experience from the United States. Cancer 2001;92:1843-1855. https://doi.org/10.1002/10970142(20011001)92:7<1843:aid-cncr1701>3.0.co;2-w

5. Gill IS, Schweizer D, Hobart MG, Sung GT, Klein EA, Novick AC. Retroperitoneal laparoscopic radical nephrectomy: the Cleveland Clinic experience. J Urol 2000;163:1665-1670. https://doi.org/10.1016/s00225347(05)67516-7

6. Portis AJ, Yan Y, Landman J, et al. Long-term followup after laparoscopic radical nephrectomy. J Urol 2002;167:1257-1262. 
7. Dunn MD, Portis AJ, Shalhav AL, et al. Laparoscopic versus open radical nephrectomy: a 9 year experience. J Urol 2000;164:1153-1159.

8. Shuford MD, McDougall EM, Chang SS, LaFleur BJ, Smith Jr JA, Cookson MS. Complications of contemporary radical nephrectomy: comparison of open vs. laparoscopic approach. Urol Oncol 2004;22:121-126. https://doi.org/10.1016/S10781439(03)00137-6

9. Swanson DA, Borges PM. Complications of transabdominal radical nephrectomy for renal cell carcinoma. J Urol 1983;129:704-707. https://doi. org/10.1016/s0022-5347(17)52321-6

10. Walther MM, Lyne JC, Libutti SK, Linehan WM. Laparoscopic cytoreductive nephrectomy as preparation for administration of systemic interleukin-2 in the treatment of metastatic renal cell carcinoma: a pilot study. Urology 1999;53:496-501. https://doi. org/10.1016/s0090-4295(98)00562-7

11. Matin SF, Madsen LT, Wood CG. Laparoscopic cytoreductive nephrectomy: the M.D. Anderson Cancer Center experience. Urology 2006;68:528-532. https:// doi.org/10.1016/j.urology.2006.03.076

12. Rabets JC, Kaouk J, Fergany A, Finelli A, Gill IS, Novick AC. Laparoscopic versus open cytoreductive nephrectomy for metastatic renal cell carcinoma. Urology 2004;64:930-934. https://doi.org/10.1016/j. urology.2004.06.052

13. Steinberg AP, Finelli A, Desai MM, et al. Laparoscopic radical nephrectomy for large (greater than $7 \mathrm{~cm}, \mathrm{~T} 2$ ) renal tumors. J Urol 2004;172:2172-2176. https://doi. org/10.1097/01.ju.0000140961.53335.04

14. Gong EM, Lyon MB, Orvieto MA, Lucioni A, Gerber GS, Shalhav AL. Laparoscopic radical nephrectomy: comparison of clinical stage T1 and T2 renal tumors. Urology 2006;68:1183-1187. https://doi.org/10.1016/j. urology.2006.08.1077

15. Stifelman MD, Handler T, Nieder AM, et al. Handassisted laparoscopy for large renal specimens: a multi-institutional study. Urology 2003;61:78-82. https:// doi.org/10.1016/s0090-4295(02)02117-9

16. Malaeb BS, Sherwood JB, Taylor GD, Duchene DA, Broder KJ, Koeneman KS. Hand-assisted laparoscopic nephrectomy for renal masses $>9.5 \mathrm{~cm}$ : series comparison with open radical nephrectomy. Urol Oncol 2005;23:323-327. https://doi.org/10.1016/j. urolonc.2005.03.0

17. Dillenburg W, Poulakis V, Skriapas K, et al. Retroperitoneoscopic versus open surgical radical nephrectomy for large renal cell carcinoma in clinical stage cT2 or CT3a: quality of life, pain, and reconvalescence. Eur Urol 2006;49:314-322. https:// doi.org/10.1016/j.eururo.2005.10.021
Etik onayı: Çalışma, Pamukkale Üniversitesi Girişimsel Olmayan Klinik Araştırmalar Etik Kurulu'nun 01/06/2020 tarih ve 60116787020/31830 sayılı toplantı onay alınmıştır.

\section{Yazarların makaleye olan katkıları}

S.Ç. çalışmanın ana fikrini ve hipotezini kurgulamıştır. S.Ç. ve Y.Ö., teoriyi geliştirmiş ve gereç ve yöntem bölümünü düzenlemiştir. Sonuçlar kısmındaki verilerin değerlendirmesini S.Ç. ve Y.Ö. yapmıştır. Makalenin tartışma bölümü S.Ç. ve Y.Ö. tarafından yazılmış, S.Ç. ve Y.Ö., gözden geçirip gerekli düzeltmeleri yapmış ve onaylamıştır. Ayrıca tüm yazarlar çalışmanın tamamını tartışmış ve son halini onaylamıştır. 